оперативно вмешаться в работу светофора и разгрузить внезапно образовавшийся затор. Управление происходит в большей степени с применением ручного режима. Использование элементов «умных систем» в комбинации со стратегическим транспортным планированием позволяет максимально рационально эксплуатировать имеющуюся транспортную инфраструктуру.

Данные, полученные в результате работы системы, позволят спроектировать модель транспортных потоков и обеспечат сбор информации для осуществления интеллектуального управления светофорами. Задача - создать систему оперативной автоматической подстройки работы светофоров под постоянно меняющуюся дорожную обстановку в реальном времени.

На практике эксплуатация системы «Умный светофор» и других элементов ИТС напрямую способствует повышению безопасности движения и ведет к сокращению выбросов в окружающую среду за счет повышения равномерности потока. Формирование «умной транспортной системы» не только способно решить вопросы транспорта и управления потоками, но также эффективно служит на благо безопасности и экологии.

1. Рунец Р.С. Транспортная инфраструктура / Р.С. Рунец // Автомобильные дороги. - 2019. - №08 (1053) - $144 \mathrm{c}$.

\title{
Дормидонтова Т.В., Хамидулин Т.Н.
}

Анализ переустройства коммуникаций и устройство наружного освещения на автомобильной дороге

Самарский государственный технический университет (Россия, Самара)

doi: $10.18411 / \mathrm{j}-05-2021-69$

\section{Аннотация}

При ремонте автомобильных дорог возникают проблемы, связанные с устранением повреждений или заменой коммуникаций. Такие проблемы требуют особого внимания. В работе рассматривался участок автомобильной дороги, на котором проводились исследования для выявления недостатков, в числе которых: устаревшие модели светильников, малая освещенность, перебои в работе оборудования, большая трата энергии, замена оборудования, и т.д. Вследствие влияния анализируемых факторов, были составлены рекомендации для переустройства коммуникаций наружного освещения.

Ключевые слова: наружное освещение, светильник, электроэнергия, электроосвещение, замена, оборудование, напряжение.

\section{Abstract}

When repairing roads, there are problems associated with repairing damage or replacing communications. Such problems require special attention. The paper considered a section of the highway, where studies were conducted to identify shortcomings, including: outdated models of lamps, low illumination, interruptions in the operation of equipment, a large waste of energy, replacement of equipment, etc. Due to the influence of the analyzed factors, recommendations were made for the reconstruction of outdoor lighting communications.

Keywords: outdoor lighting, lamp, electricity, electric lighting, replacement, equipment, voltage. 
На анализируемом участке автомобильной дороге запроектировано устройство линии наружного электроосвещения с применением светильников, установленных на стальных опорах и подключенных самонесущими изолированными проводами. Расчетная мощность наружного освещения участков составляет 10,05кВт.

На основе проведенного сравнительного анализа технических характеристик светодиодных, индукционных, газоразрядных светильников, а также сравнения закупочной стоимости с учетом расходов в процессе эксплуатации (замена лампочек их ремонт и.т.д.), затрат на выкуп мощности и построения графика капитальных вложений по времени, был предложен светильник ЖКУ39-150-015-02 как наиболее эффективный по качеству света, уровню энергопотребления и экономичности по эксплуатационным затратам, таблица 1 .

Светильник предназначен для наружного освещения улиц, шоссе, магистралей, парков. Он эффективно и равномерно освещает проезжую часть и тротуары, не создавая бликов и мерцания. Корпус отличается высокой степенью антикоррозионной, пыле- и влагозащищенности. Модель может крепиться на столбах или специальных опорах на высоте 8-12м. Дизайн уличного светильника выполнен в традиционном стиле с учетом использования зеркальной натриевой лампы «Рефлакс».

Выбор параметров осветительных приборов и шаг их размещения выполнялся на основании расчетов, выполненных в программе Light-in-Night Road 5.0.

В ходе проведенного исследования установлено, что общая длина участка наружного освещения составляет 2311метров, категория электроснабжения - III, следовательно при подключении светильников к сети освещения следует соблюдать порядок фазировки: A-B-C, A-B-C и т.д. Для улучшения коэффициента мощности распределительных сетей в светильниках необходимо предусмотреть установку компенсаторов реактивной мощности. Учет потребления электроэнергии следует осуществлять многотарифным счетчиком с цифровым интерфейсом передачи данных установленным в исполнительном пункте ИП «Горсвет».

Таблицุа 1

Таблииа сравнения светильников

\begin{tabular}{|c|c|c|c|c|}
\hline $\begin{array}{l}\text { Параметры } \\
\text { светильника }\end{array}$ & $\begin{array}{c}\text { SO 06-008 } \\
\text { индукционный }\end{array}$ & ЖКУ-16-250-001 & $\begin{array}{c}\text { Светодиодный } \\
\text { УКСС-150м }\end{array}$ & $\begin{array}{c}\text { ЖКУ-39-150-015- } \\
\text { 02-УХЛ1 }\end{array}$ \\
\hline 1 & 2 & 3 & 4 & 5 \\
\hline $\begin{array}{c}\text { Срок службы } \\
\text { излучающего } \\
\text { элемента, ч } \\
\end{array}$ & 100000 & До 20000 & До 50000 & До 36000 \\
\hline $\begin{array}{c}\text { Потребление } \\
\text { электроэнергии, Вт }\end{array}$ & $<160$ & $>300$ & $<190$ & $<160$ \\
\hline Пусковой ток, А & 0,72 & 4,5 & 0,86 & 0,72 \\
\hline Потребляемый ток, А & 0,72 & 1,27 & 0,86 & 0,72 \\
\hline $\begin{array}{c}\text { Устойчивость к } \\
\text { перепадам } \\
\text { напряжения, В } \\
\end{array}$ & $100-300$ & не устойчив & $176-264$ & $100-320$ \\
\hline $\begin{array}{c}\text { Нагрев источников } \\
\text { света, градус C }\end{array}$ & 80 & $200-300$ & 150 & 150 \\
\hline $\begin{array}{c}\text { Коэффициент } \\
\text { пульсации }\end{array}$ & 0,4 & 4,9 & 0,4 & \\
\hline $\begin{array}{c}\text { Контрастность и } \\
\text { цветопередача }\end{array}$ & Высокая $>85 \mathrm{Ra}$ & Низкая 30-50Ra & Высокая $<80 \mathrm{Ra}$ & Низкая 30-50Ra \\
\hline Степень защиты & 1P54 & 1P54 & $1 \mathrm{P} 65$ & $1 \mathrm{P} 67$ \\
\hline Вес светильника, кг & 9,0 & 6,8 & 14,3 & 3,1 \\
\hline $\begin{array}{c}\text { Время пуска } \\
\text { источника света }\end{array}$ & $\begin{array}{c}\text { Максимально } 0,5 \\
\text { с }\end{array}$ & $\begin{array}{c}\text { От } 3 \text { до } 15 \text { минут } \\
\text { (время } \\
\text { разогрева) }\end{array}$ & $\begin{array}{c}\text { максимально } 0,5 \\
\text { секунды }\end{array}$ & $\begin{array}{c}\text { От } 3 \text { до15 минут } \\
\text { (время } \\
\text { разогревания } \\
\text { ламп) } \\
\end{array}$ \\
\hline
\end{tabular}




\begin{tabular}{|c|c|c|c|c|}
\hline $\begin{array}{c}\text { Температурные } \\
\text { режимы работы во } \\
\text { время эксплуатации, }{ }^{\circ} \\
\text { C }\end{array}$ & От -50 до +70 & $\begin{array}{c}\text { От -40 до +40 } \\
\text { (при низких } \\
\text { температурах } \\
\text { запуск систем } \\
\text { затруднен) } \\
\end{array}$ & От -40 до +60 & От -40 до +60 \\
\hline $\cos \varphi$ & $0,95-0,98$ & $0,6-0,8$ & 0,95 & 0,98 \\
\hline $\begin{array}{c}\text { Перезапуск после } \\
\text { перепада, U }\end{array}$ & Мгновенно & $\begin{array}{c}\text { После остывания } \\
\text { лампы }\end{array}$ & Мгновенно & $\begin{array}{c}\text { После остывания } \\
\text { лампы }\end{array}$ \\
\hline $\begin{array}{c}\text { Цветовая } \\
\text { температура } \\
\end{array}$ & $5000 \mathrm{~K}$ & $2000 \mathrm{~K}$ & $4000 \mathrm{~K}$ & $2000 \mathrm{~K}$ \\
\hline $\begin{array}{c}\text { Потеря светового } \\
\text { потока }\end{array}$ & $\begin{array}{c}20-25 \% \text { после } \\
70000 \text { час }\end{array}$ & $\begin{array}{c}20-40 \% \text { после } \\
5000 \text { час }\end{array}$ & $\begin{array}{c}30 \% \text { после } 50000 \\
\text { час }\end{array}$ & $\begin{array}{c}20-40 \% \text { после } \\
36000 \text { час }\end{array}$ \\
\hline Гарантия & 5 лет & & 5 лет & 3 года \\
\hline $\begin{array}{c}\text { Световой поток с } \\
\text { учетом } \\
\text { коэффициента } \\
\text { использования } \\
\text { светового потока и } \\
\text { коэффициента запаса } \\
\end{array}$ & 12000 & 14300 & 14250 & 14355 \\
\hline $\begin{array}{c}\text { Количество } \\
\text { светильников, } \\
\text { необходимое для } \\
\text { достижения } \\
\text { необходимой } \\
\text { освещенности } \\
\end{array}$ & 1 & 1 & 1 & 1 \\
\hline $\begin{array}{c}\text { Экономия } \\
\text { электроэнергии }\end{array}$ & $0 \%$ & $0 \%$ & $30 \%$ & $40 \%$ \\
\hline $\begin{array}{c}\text { Стоимость } \\
\text { светильника с } \\
\text { лампой (руб.) } \\
\end{array}$ & $11830-9819$ & 4201 & 23130 & 5268 \\
\hline $\begin{array}{c}\text { Количество } \\
\text { светильников, шт. }\end{array}$ & 81 & 81 & 81 & 81 \\
\hline $\begin{array}{c}\text { Стоимость всех } \\
\text { светильников, руб. }\end{array}$ & 843210 & 340281 & 187110 & 426708 \\
\hline $\begin{array}{c}\text { Возможность } \\
\text { управления световым } \\
\text { потоком } \\
\end{array}$ & нет & Нет & нет & есть \\
\hline $\begin{array}{c}\text { Мощность всех } \\
\text { светильников, кВт, с } \\
\text { учетом димирования }\end{array}$ & 12,15 & 22,68 & 15,39 & 9,11 \\
\hline $\begin{array}{c}\text { Стоимость } \\
\text { технологического } \\
\text { подключения, руб } \\
(600 \text { руб за кВт) }\end{array}$ & 7290 & 13608 & 9234 & 5466 \\
\hline $\begin{array}{c}\text { Время работы, часов } \\
\text { в год }\end{array}$ & 4380 & 4380 & 4380 & 4380 \\
\hline $\begin{array}{c}\text { Годовое потребление } \\
\text { электроэнергии, руб } \\
(5 \text { руб за кВт*час) } \\
\end{array}$ & 266085 & 496692 & 337041 & 199509 \\
\hline $\begin{array}{c}\text { Годовые расходы на } \\
\text { обслуживание } \\
\text { свеильников (из } \\
\text { расчета } 200 \text { руб в год } \\
\text { на каждый } \\
\text { светильник и } 1500 \\
\text { руб в год на } \\
\text { светильник ЖКУ-16- } \\
\text { 250) } \\
\end{array}$ & 16200 & 121500 & 16200 & 16200 \\
\hline $\begin{array}{c}\text { Расходы на } \\
\text { электроэнергию за } 5 \\
\text { лет }\end{array}$ & 1330425 & 2483460 & 1685205 & 997545 \\
\hline
\end{tabular}




\begin{tabular}{|c|c|c|c|c|}
\hline $\begin{array}{c}\text { расходы на } \\
\text { обслуживание } \\
\text { светильников за 5 лет }\end{array}$ & 81000 & 607500 & 81000 & 81000 \\
\hline $\begin{array}{c}\text { Итого расходов за 5 } \\
\text { лет эксплуатации с } \\
\text { учетом } \\
\begin{array}{c}\text { первоначальных } \\
\text { вложений }\end{array}\end{array}$ & 2254635 & 3431241 & 19533315 & 1505253 \\
\hline
\end{tabular}

В соответствии с ГОСТ Р 52766-2007 нормируемая средняя горизонтальная освещенность покрытия автомобильной дороги должна соответствовать показателю 8лк, опоры освещения должны быть установлены на расстояние не менее 4 метров от края проезжей части.

В данной работе был сформирован состав оборудования, он представляет собой:

— бесконтактный коммутатор БК-100-06 - базовый прибор, реализующий все функции непосредственного управления и контроля участка сети уличного освещения;

- средство связи с диспетчером (GSM-модем), возможность резервирования канала связи для обеспечения надежной связи с ЦДП;

- многотарифный счетчик электроэнергии с цифровым интерфейсом передачи данных для организации учета потребленной электроэнергии;

— устройство грозозащиты оборудования;

— блок предохранителей или автоматов;

- вводной рубильник.

В ходе анализа были сформированы основные технические характеристики пункта питания наружного освещения с комплектацией прибором БК-100-06, рисунок 1 , таблица 2.

Таблица 2

Технические характеристики пункта питания наружного освещеения

\begin{tabular}{|c|c|}
\hline Наименование & Значение \\
\hline Параметры питающей сети & $\begin{array}{r}\text { Трехфазная, трехфазная с глухозаземленной нейтралью } \\
\text { сеть переменного тока 220B }+10 \%-15 \%, 50 Г ц\end{array}$ \\
\hline $\begin{array}{c}\text { Уровни срабатывания токовой } \\
\text { защиты:М } \\
\text { Номинальный ток плавкой } \\
\text { вставки, А, не более }\end{array}$ & $40 \mathrm{~A}$, \\
\hline $\begin{array}{c}\text { Габаритные размеры не более, } \\
\text { мм }\end{array}$ & $25 \mathrm{~A}$ \\
\hline Масса не более, кг & $260 \mathrm{x} 480$ \\
\hline
\end{tabular}
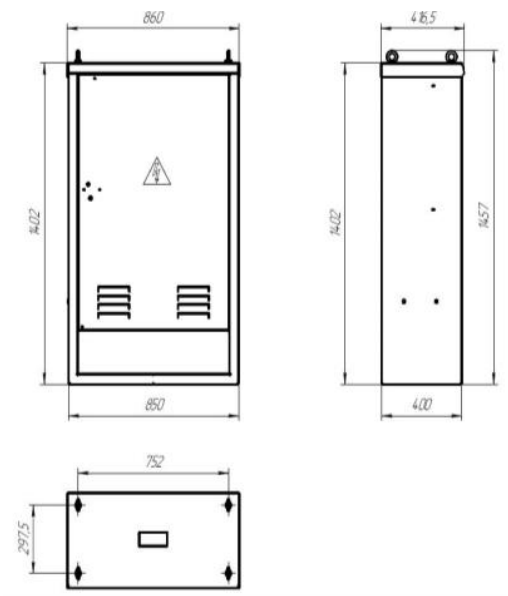

Рисунок 1 - Основные размеры оборудования 
Для снижения боковых сил морозного пучения фундаменты опор необходимо обернуть слоем евроруберойда (стеклоизола). Класс бетона фундаментов опор электроосвещения по прочности принять (в соответствии с требованиями п.6.1.6 СП 63.13330.2012 «Бетонные и железобетонные конструкции. Основные положения») В15. Из геологического отчета следует вывод что грунт, взятый из карьера, не агрессивен к маркам бетона W4, W6, W8, следовательно согласно требованиям таблицы Г2 ГОСТ 31384-2008 марка бетона фундамента по морозостойкости необходимо принять F100, по водонепроницаемости - W6.

\section{$* * *$}

1. Анцев, И. Б. Основы проектирования внутренних электрических сетей / И.Б. Анцев, В.Н. Силенко. - М.: Проспект Науки, 2010. - 272 с.

2. Сибикин, Ю.Д. Электроснабжение: Учебное пособие / Ю.Д. Сибикин, М.Ю. Сибикин. - М.: РадиоСофт, 2013. - 328 с.

3. Щербаков, Е.Ф. Электроснабжение и электропотребление в строительстве: Учебное пособие / Е.Ф. Щербаков, Д.С. Александров, А.Л. Дубов. - СПб.: Лань, 2012. - 512 с.

4. СП 52.13330.2016. Естественное и искусственное освещение. Актуализированная редакция СНиП 23-05-95*

5. ГОСТ Р 54350-2015. Приборы осветительные. Актуализированная редакция ГОСТ 17677-82*

Мельникова Т.Е., Адуллина 3.М., Степанова И.С. Перспективы развития автономных грузовых автотранспортных средств в России с учетом зарубежного опыта

Московский автомобильно-дорожный государственный технический университет (МАДИ)

(Россия, Москва)

doi: $10.18411 / \mathrm{j}-05-2021-70$

\section{Аннотация}

В данной статье рассматриваются беспилотные автотранспортные средства. Они являются актуальными в наше время. Беспилотники были протестированы в Китае и Соединённых Штатах Америки. Чтобы следовать по выбранному маршруту, автомобилю приходится использовать разные устройства, такие как: видеокамеры, датчики положения и инерции, радары, GPS-навигатор и другие. В связи с тем, что интеллектуальное программное обеспечение маршрутизации будет предоставлять грузовику данные о трафике в реальном времени, позволяя тем самым ему адаптировать свой маршрут, чтобы избежать встречных перегрузок.

Ключевые слова: беспилотное транспортное средство, нормативно-правовое регулирование, безопасность дорожного движения.

\section{Abstract}

This article discusses self-driving vehicles. They are relevant in our time. The drones have been tested in China and the United States. To follow the chosen route, the car has to use different devices, such as video cameras, position and inertia sensors, radars, GPS-navigator, and others. Due to the fact that intelligent routing software will provide the truck with realtime traffic data, thus allowing it to adapt its route to avoid oncoming congestion.

Keywords: self-driving vehicle, legal regulation, road safety.

\section{Беспилотные грузовые перевозки}

Еще 10 лет назад беспилотные перевозки грузов казались фантастикой и далеким будущим. Однако уже сегодня наблюдается активное развитие проектов беспилотных грузовиков, их успешные тестирования и постепенное введение в эксплуатацию. Беспилотные тягачи с полуприцепами уже сейчас обладают рядом 